\title{
HOW REPRESENTATIVE ARE AMS MEMBERSHIP SURVEYS?
}

\author{
by Leslie M. Hartten and Margaret A. LeMone
}

A 2010 Bulletin article by Hartten and LeMone (hereafter Hartten-LeMone) used demographic data collected by 3 AMS member surveys, conducted over a span of 12 years, to describe the time-varying nature of the field of meteorology/atmospheric sciences in terms of gender and race. The AMS survey data were augmented by other datasets collected either by the AMS and UCAR or by authors of Bulletin articles. These ancillary surveys were assumed to be broadly representative of the field, with a strong but not exclusive emphasis on the United States. Two questions typically arise with data such as these: Are surveys conducted by or on behalf of the AMS truly representative? And can we use occasional surveys to detect trends within the field, so as to possibly make projections for the short-term future? Data from annual National Science Foundation (NSF) surveys of graduate students and academic degrees granted can help answer both questions.

Statistics compiled by NSF indicate that the number of female graduate students in the atmospheric sciences has increased fairly steadily since the 1972-73 academic year (Fig. 1, top). The percentage of women has increased as well, with the sharpest increase (from about 1995-2003) coinciding with a drop in the number of male graduate students (1993-2001) that was followed by a sluggish recovery until jumping back to pre-1993 levels with the onset of the "Great Recession" in 2008. This increase in the

AFFILIATIONS: HARTTEN-University of Colorado/Cooperative Institute for Research in Environmental Sciences (CIRES), and NOAA/Earth System Research Laboratory, Physical Sciences Division, Boulder, Colorado; LEMONE-NCAR*/Mesoscale and Microscale Meteorology Division, Boulder, Colorado

* The National Center for Atmospheric Research is sponsored by the National Science Foundation

CORRESPONDING AUTHOR: Leslie M. Hartten, Cooperative Institute for Research in Environmental Sciences, University of Colorado, 216 UCB, Boulder, Colorado 80309-0216

E-mail: Leslie.M.Hartten@noaa.gov

DOI:10.1175/BAMS-D-13-00058.I

(C)2014 American Meteorological Society percentage of women caused in part by a decrease in the number of men was also noted in some subsets of the 2005 AMS Member Survey data presented in Hartten-LeMone (c.f. their Figs. 3 and 4). Thus, is it not surprising that the data in Fig. 1 (bottom), based on a corrected version of Hartten-LeMone's Fig. 8, follow the five-year running mean NSF percentages almost exactly (Fig. 1, bottom). See the sidebar for an explanation of the corrected plot.

From an "outcomes" perspective, the NSF data appear to support the representativeness of gender percentages based on the AMS survey data. What about from a "sampling" perspective? The com-
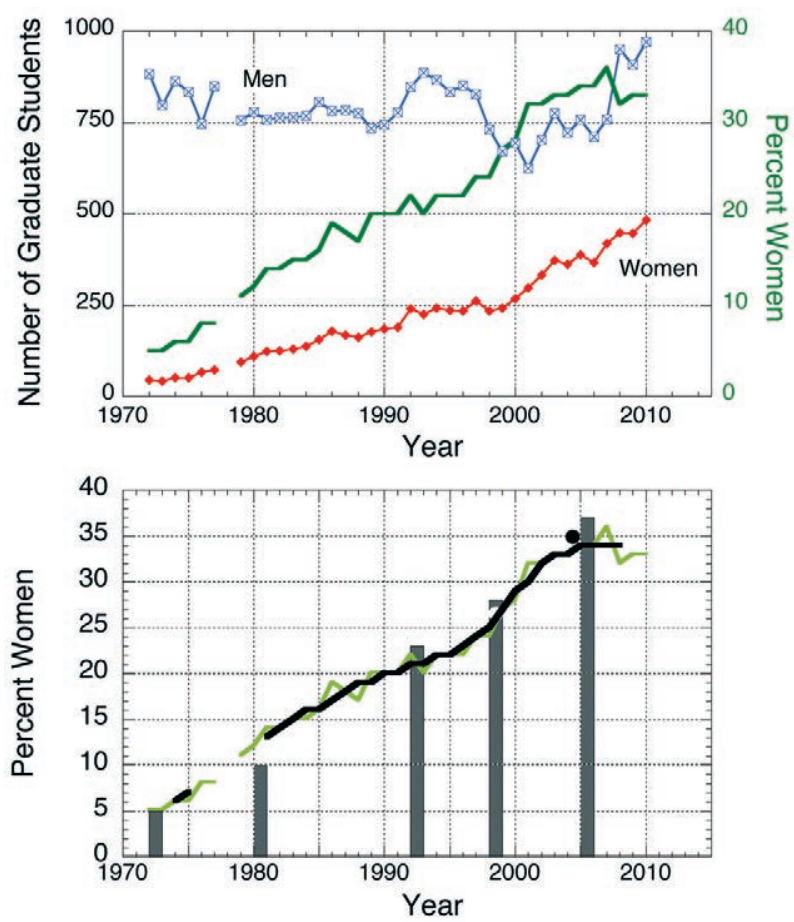

Fig. I. (top) The number of male (blue squares) and female (red diamonds) graduate students studying atmospheric sciences, together with the proportion of women (green line). "Year" refers to the fall of an academic year. Data are from NSF/NIH surveys of graduate students and postdocs in science and engineering. (bottom) The same proportion of female graduate students (thin line) and its five-year running mean (thick line), together with values from AMS sources (c.f. Fig. SBI and Table I). 
bined number of male and female graduate students counted by NSF during several years, including those plotted in the corrected Hartten-LeMone figure, is given in Table $1,{ }^{1}$ as is the number of atmospheric sciences graduate students from AMS-related sources. Before comparing the two datasets, some comments on the AMS numbers are in order.

In Table 1, AMS numbers are of three types: those based on direct member surveys, those based on surveys of university departments and published in the Curricula series, and those based on ad hoc surveys published in the Bulletin. The Curricula numbers in the Table exceed 1,000 until 1993; these drop below
1,000 by 1998 , and to 550 by 2004 , reflecting fewer universities reporting. Moreover, the methods for deriving the final numbers differed slightly. As detailed in Table 1, the 1992 data in Fig. SB1 (and Fig. 8 of Hartten-LeMone) were gleaned by the second author from individual university listings in the Curricula. Some filtering was done to eliminate academic departments that clearly did not involve atmospheric sciences, but it is possible some oceanographers and hydrologists were included. Based on Curricula summaries, the data for 1998 and 2005 explicitly applied to the atmospheric sciences. ${ }^{2}$ However, only a modest subset of the responding university

\footnotetext{
${ }^{1}$ The NSF statistics from 1972-74 are "not strictly comparable with 1975 and later data" because of the inclusion of more fields and more institutions over that period (NSF 1998).

${ }^{2}$ Because the data for 1998 and 2005 were in summary form, it is possible that the people doing the filtering-and hence the process employed to include only "atmospheric"-differ slightly from year to year, and it is probable that the filtering process was slightly different from that used by LeMone for the 1992 data.
}

\section{CORRIGENDUM: THE EVOLUTION AND CURRENT STATE OF THE ATMOSPHERIC SCIENCES “PIPELINE”}

Two errors in the statistics presented in Hartten-LeMone regarding the proportion of women graduate students in meteorology have recently been brought to our attention. Here we correct those errors and clarify some details about the ancillary datasets involved.

Figure 8 of Hartten-LeMone overestimates the percentage of women graduate students in the atmospheric sciences for the years labeled 1997 and 2004; it also assigns the wrong dates to those percentages. Figure SBI, the corrected and updated version, reveals smaller percentages for $1998-99^{\mathrm{a}}$ and $2005-06^{\mathrm{b}}(28 \%$ and $37 \%$, respectively) than in the original figure (39\% and $50 \%)$. The incorrect percentages were caused by a purely arithmetical problem. The corrected values and dates do not change the fundamental conclusion drawn by Hartten-LeMone: the proportion of women atmospheric scientists in graduate school has increased considerably since the very small values recorded by Simpson and LeMone in their 1974 Bulletin article. The correction does show that the change over the last few decades has been less dramatic than originally thought, more linear than exponential.

a Reexamination of the data prompted a slight tweaking of the dates as well as the percentages. The year was changed to 1998 after a painstaking reading of the statistical summary in AMS/UCAR (2000), which lists "current" majors "through summer 1999." However, the university statistics therein were not uniform, with some listing students for the 1997-99 reporting period.

b The year 2004 was changed to 2005 to be consistent with the notation "current majors."

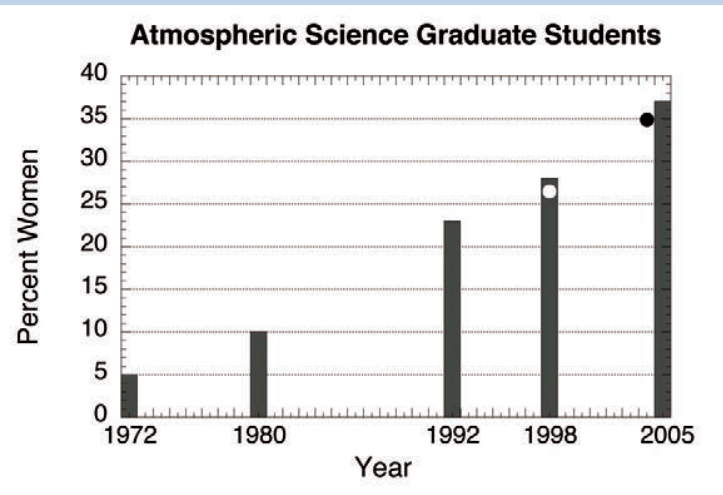

FIG. SBI. The proportion of women among graduate students studying atmospheric sciences, corrected from Hartten and LeMone (2010, Fig. 8). The 1972 value is from Simpson and LeMone (1974), who described it as the "maximum possible," and the 1980 estimate is from LeMone and Waukau (1982). The 1998 value shown by a white $\operatorname{dot}(26.5 \%)$ represents respondents to the 1999 AMS Member Survey who identified themselves as graduate students. The 2004 value shown by a black dot (35\%) represents students with previous bachelor's or master's degrees who responded to the 2005 AMS Member Survey. The other values are from statistics gathered by AMS/UCAR. 


\section{BEACON}

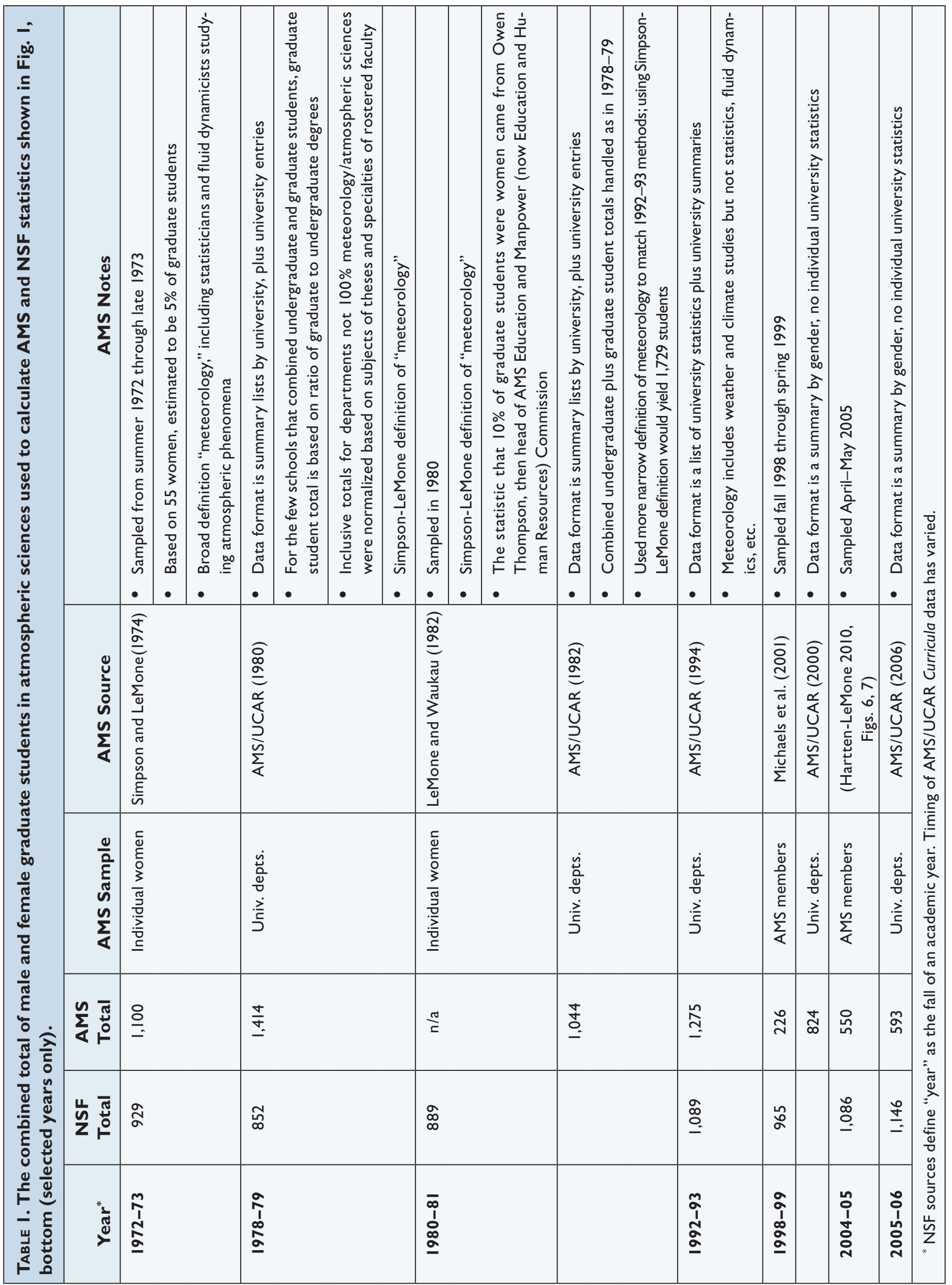


departments reported fully. For 1998, M.S. and Ph.D. students were reported by gender for only 35 of the 55 institutions reporting M.S. students and the 46 reporting Ph.D. students. The situation is even worse for 2005; out of only 30 institutions reporting demographic data on graduate students, just 16 reported M.S. and M.A. students by gender while all 30 institutions reported Ph.D. students by gender. Fortunately, increased response to the member surveys has partially compensated for the drop in response in the Curricula, as illustrated by the increase in the number of graduate students
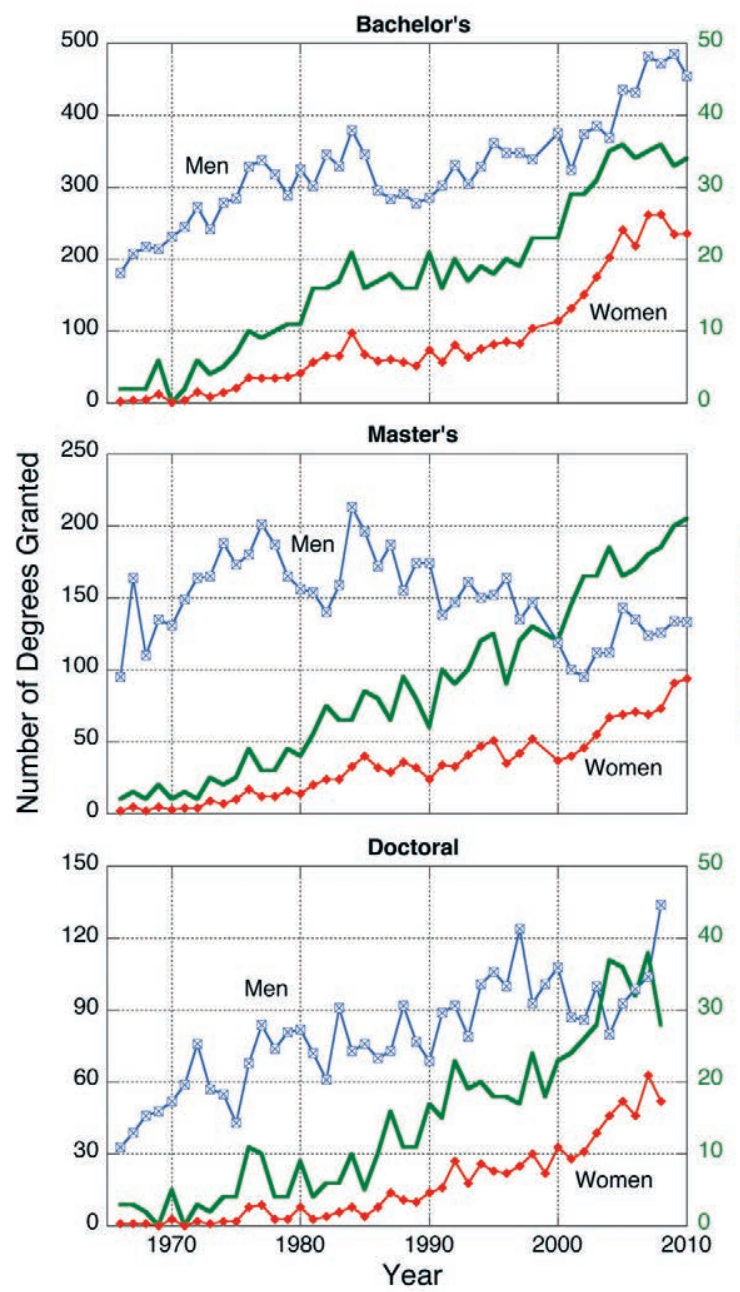

Fig. 2. Number of men (blue squares) and women (red diamonds), and the proportion of women (solid green line), who received (top) bachelor's, (center) master's, and (bottom) doctoral degrees in atmospheric sciences in the United States. Most data (1966-2008) from NSF (20Ilb); other data (2009-10) from NSF (20I3). "Year" refers to the fall of an academic year. Note that each left $y$ axis has a different range. participating in the 2005 AMS Member Survey relative to the 1999 survey.

The net effects of differing methods and changing participation in AMS-related estimates are total numbers that vary with respect to the more stable NSF totals, but female-to-total ratios that are similar. The number of graduate students counted by the Curricula was within 15\% of NSF values in the 1982 and 1990s' surveys but was only 52\% of NSF values in 2005. The 2005 AMS Member Survey number, at $48 \%$ of NSF values, was comparable to the diminished Curricula number. The number of graduate students calculated from SimpsonLeMone for 1972 was, like the Curricula estimates from 1980 and 1992, 15\%-20\% higher than NSF values. However, Fig. 1 shows that the female proportions from all these sources are very similar in any given year, in spite of the sometimes large sample differences.

Finally, we examine trends based on annual NSF statistics regarding the number of degrees in atmospheric sciences granted to men and to women. ${ }^{3}$ Figure 2 shows increasing numbers and percentages for women in all three degree categories. There was about 3 times as much growth from 1990 to 2010 as in the previous 24 years-two-thirds of it in the 2000 s. While the proportion of women increases with time for all degrees, it is again influenced by lower numbers of men receiving master's degrees after the peak in 1984. If we compare the trends for the different degree categories after 1984, there are some interesting differences. For bachelor's degree recipients, there is a sustained recovery until 2007, while the master's degrees recipients drop until 2002 and never return to 1984 levels. The Ph.D. recipient curve shows a slow and choppy increase through the period. The relatively sluggish growth at the master's level suggests that more bachelor's degree recipients are entering the workforce, and/or that fewer students from other undergraduate fields are pursuing graduate study in the atmospheric sciences

\footnotetext{
${ }^{3}$ The NSF statistics for bachelor's and master's degrees were computed by NSF from data extracted from a different survey than were the statistics for doctoral degrees, which leads to the possibility of "atmospheric chemistry and climatology" degrees being included in the latter but not in the former. In addition, there is a data discontinuity in the bachelor's and master's degree statistics, with statistics from 2000 forward based on data drawn from a larger pool of institutions than used for the 1966-99 statistics.
} 
at the master's level. Surprisingly, the difference between the number of men and women receiving bachelor's or doctoral degrees has remained fairly constant for almost five decades.

The consistency in the percentages of women revealed in Fig. 1 (bottom), despite different methodologies and only partially overlapping samples, is encouraging and indicates that the NSF data are sufficient to provide the AMS with current gender demographics among degree recipients and graduate students. We cannot say if this applies to racial demographics, where the ratios are much smaller and the AMS data record is shorter, or for those who are finished with their education and no longer sampled by NSF. However AMS surveys can-as they have in the past-be used to find out in more depth how all meteorologists and atmospheric scientists are doing as they progress through their careers, and how the AMS can be more relevant to them.

ACKNOWLEDGMENTS. We are grateful to Xiaoqing $\mathrm{Wu}$ and Bill Gallus of Iowa State University for surveying colleagues and then expressing their skepticism to us regarding the 50\% number for 2004 in Fig. 8 of HarttenLeMone; and to Rajul Pandya of UCAR for directing us to the most recent NSF statistics. This work was supported by the Physical Sciences Division of the NOAA Earth System Research Laboratory and by the Mesoscale and Microscale Meteorology Division of NCAR.

\section{FOR FURTHER READING}

American Meteorological Society, and University Corporation for Atmospheric Research, 1980: Curricula in the Atmospheric and Oceanographic Sciences. AMS/UCAR, 320 pp.

—, and —-1982: Curricula in the Atmospheric and Oceanographic Sciences. AMS/UCAR,369 pp.

- - and - 1994: Curricula in the Atmospheric, Hydrologic, and Related Sciences: Colleges and Universities in the United States, Puerto Rico, and Canada. AMS/UCAR, 594 pp.

—-, and - 2000: Curricula in the Atmospheric, Oceanic, Hydrologic, and Related Sciences: Colleges and Universities in the United States and Canada. AMS/ UCAR, 501 pp.

- and - 2006: Curricula in the Atmospheric, Oceanic, Hydrologic, and Related Sciences: Colleges and Universities in the United States and Canada. AMS/ UCAR. [Available online at http://nldr.library.ucar .edu/repository/collections/UNPC-000-000-000-003.]
Hartten, L. M., and M. A. LeMone, 2010: AMS membership survey results: The evolution and current state of the atmospheric sciences "pipeline.” Bull. Amer. Meteor. Soc., 91, 942-956, doi:10.1175/2010BAMS2537.1.

LeMone, M. A., and P. L. Waukau, 1982: Women in meteorology. Bull. Amer. Meteor. Soc., 63, 1266-1276, doi:10.1175/1520-0477(1982)063<1266:WIM>2.0 .CO;2.

Michaels, M., M. Shepard, S. Aberson, H. Friedman, and K. Murphy, 2001: Survey results of society membership: The face of our profession at the threshold of the new millennium. Bull. Amer. Meteor. Soc., 82, 1331-1352. doi:10.1175/1520 -0477(2001)082<1331:SROSMT>2.3.CO;2.

Murillo, S. T., R. E. Pandya, R. Y. Chu, J. A. Winkler, R. Czujko, and E. M. C. Cutrim, 2008: An overview and longitudinal analysis of the demographics of the AMS. Bull. Amer. Meteor. Soc., 89, 727-733. doi:10.1175/BAMS-89-5-727.

National Science Foundation, 1998: Women, Minorities, and Persons With Disabilities in Science and Engineering: 1998. Report NSF 99-338, 330 pp. [Available online at www.nsf.gov/statistics/wmpd/.]

_-, 2004: Women, Minorities, and Persons with Disabilities in Science and Engineering: 2004. Report NSF 04-317, 292 pp. [Available online at www.nsf .gov/statistics/wmpd/.]

—_, 2008: Integrated Science and Engineering Resources Data System (WebCASPAR). Accessed 13 March 2013. [Available online at https://webcaspar.nsf.gov.] _ 2009: Women, Minorities, and Persons with Disabilities in Science and Engineering: 2009. Report NSF 09-305, 285 pp. [Available online at www .nsf.gov/statistics/wmpd/.]

_ 2011a: Women, Minorities, and Persons with Disabilities in Science and Engineering: 2011. Special Report NSF 11-309. [Available at www.nsf.gov /statistics/wmpd/.]

__ 2011b: Science and Engineering Degrees: 1966-2008. Detailed Statistical Tables NSF 11316. [Available online at www.nsf.gov/statistics /nsf11316/.]

_- 2013: Women, Minorities, and Persons with Disabilities in Science and Engineering: 2013. Special Report NSF 13-304, 262 pp. [Available online at www .nsf.gov/statistics/wmpd/.]

Simpson, J., and M. LeMone, 1974: Women in meteorology. Bull. Amer. Meteor. Soc., 55, 122-131, doi:10.1175/1520-0477(1974)055<0122:W IM >2.0 .CO;2. 